Article

\title{
Comparison of Sustainable Environmental, Social, and Corporate Governance Value Added Models for Investors Decision Making
}

\author{
Marie Pavláková Dočekalová * and Alena Kocmanová \\ Department of Economics, Faculty of Business and Management, Brno University of Technology, Kolejní 4, \\ Brno 61200, Czech Republic; kocmanova@fbm.vutbr.cz \\ * Correspondence: Docekalova@fbm.vutbr.cz; Tel.: +420-541-142-638
}

Received: 11 January 2018; Accepted: 27 February 2018; Published: 28 February 2018

\begin{abstract}
The Sustainable Value-Added Model is a new approach in value-oriented strategic management that focuses on maximizing the value that is created by non-financial sustainability indicators. The objective of this paper is to refine the calculation of sustainable added value by incorporating environmental, social, and corporate governance sustainability indicators, assigning weights to the indicators and, by alternative methods, assigning target values to the indicators. Ten alternative models of Sustainable Environmental, Social, and Corporate Governance Value Added were created. The models encompass 11 environmental, social, and corporate governance indicators of sustainability, and two economic indicators (Earnings before Interest, Taxes, Depreciation and Amortization, and Value Added). Indicator values are related to the target values that represent the opportunity costs. The quality of the models was assessed by statistical methods, i.e., the Receiver Operating Characteristic curve, Gini index, and Kolmogorov-Smirnov statistic. The results of these statistics show sufficient quality of all the models proposed. The most accurate model is that with the economic indicator Value Added and target values that are based on the values of the company with the best economic results.
\end{abstract}

Keywords: corporate sustainability; sustainable value added; ESG indicators; non-financial indicators; benchmarking; Data Envelopment Analysis

\section{Introduction}

Various stakeholders are having an increasing influence and it is becoming obvious that the traditional attitude towards evaluating the economic performance of a company and its reporting are no longer sufficient $[1,2]$. Companies adopt measures and implement tools that are aimed at ensuring sustainability and long-term prospects. In the context of corporate sustainability it is necessary to create appropriate models to measure corporate sustainability that take into account the impact of the business on the community and stakeholders. Many authors deal with the issue of sustainability at the corporate level and its relationship to corporate performance [3-5]. In corporate practice, there is not yet a consistent approach to the application of tools for measuring and assessing sustainability. Use of these tools varies in business practice, which in turn, makes it difficult to make comparisons [6]. Composite indices are a relatively new approach to measuring and evaluating sustainability [7-11]. Despite their indisputable advantages, their development is accompanied by many difficulties. The basic problem is primarily the dimensionality of the very subject of the solutions that are impacting the environmental, social, economic, and corporate governance perspective of sustainability and their interactions.

Currently, in the international context, there is a growing emphasis on determining whether a company is able to increase its value and provide an appropriate return on investment for creditors. The basic general aim of most businesses is to maximise and increase market value in the long term. 
Authors [12,13] investigated going public drivers in Poland and Czech Republic and conclude that a considerably larger number of financial managers are motivated by the establishment of the firm's market value. In practice, the most commonly used method of measuring and assessing the financial and economic performance of a company is fundamental or technical analysis, which assesses the company from the economic point of view based on an analysis of financial statements and on the basis of Economic Value Added, but investors are aware that they need financial and non-financial indicators to decide on their investments. This is why contemporary economic theoreticians, mainly under pressure from investors and other stakeholder groups, prefer the idea based on the presumption that the economic problems of our time have to be solved by integrating environmental, social, and economic performance in corporate decision-making.

This article aims to modify the original concept of calculating Sustainable Value Added (SVA) and to determine other possible approaches to the Sustainable Environmental, Social, and Corporate Governance Value Added (SESG $\mathrm{VA}_{\mathrm{VA}}$ ) model design, and thus give accuracy to the calculation of sustainable value added for businesses in the manufacturing industry, and, at the same time, to evaluate the quality of the proposed SESG ${ }_{V A}$ models.

\section{Theoretical Approach to Sustainable Value}

From an economic point of view, value can be viewed through the prism of utilized resources, which represents a holistic approach to value creation and is based on the interaction of resources. Porter and Kramer [14] came up with a concept of value as something beneficial for both the company and the society. They point out that the internal economic costs approach needs to be extended to include social costs and benefits that contribute to a long-term sustainability. The current concepts of sustainable value (SV) take into account the efficiency and effectiveness of environmental and social dimensions of sustainability. Eco-efficiency and socio-efficiency express the use of natural and social resources in relation to its economic activity. Improved efficiency leads to an increase in corporate sustainability [15]. Eco-efficiency describes the degree to which the company makes use of the environmental resources in reverse proportion to its economic output (e.g., EUR/tonnes of $\mathrm{CO}_{2}$ ). Social-efficiency can be calculated as the ratio of the added value to the social impact of the company (e.g., EUR/work injury). SV allows for establishing the value of environmental and social resources in monetary terms. Investors are very interested in knowing how much businesses contributed to the achievement of environmental, social and economic objectives, and SV provides such information.

The concept of Sustainable Value Added (SVA) was first published in 2002 by German authors Frank Figge and Tobias Hahn [16]. Since the introduction of SVA several studies have been conducted on the macroeconomic and microeconomic levels [11,15-19].

The SVA created by the company can be calculated according to Equation (1) [11]:

$$
\mathrm{SV}=\frac{1}{n} \sum_{i=1}^{n}\left(\frac{y}{x_{i}}-\frac{y^{*}}{x_{i}^{*}}\right) x_{i}
$$

where: $n$-number of forms of capital considered; $y$-value added (output) of the company; $y^{*}$ —value added (output) of the benchmark; $x_{i}$-amount of capital $i$ used by the company; $x_{i}{ }^{*}$-amount of capital $i$ used of benchmark; $y^{*} / x_{i}^{*}$-opportunity cost. In the SVA model the considered $x_{i}$ resources are: $\mathrm{CO}_{2}$ emissions [ $\mathrm{t}$ ] $\mathrm{CH}_{4}$ emissions [ $\mathrm{t}$ ] $\mathrm{SO}_{2}$ emissions [ $\mathrm{t}$ ], $\mathrm{NO}_{\mathrm{x}}$ emissions [ $\mathrm{t}$ ], $\mathrm{CO}$ emissions [ $\mathrm{t}$ ], $\mathrm{PM}_{10}$ [t], and Work accidents [number].

Even the authors themselves recognize that this model of SV measurement is imperfect and does not say whether the company is sustainable; it only indicates that it uses its resources in a more sustainable way than the benchmark. The SV model has its opponents [20-22] who criticize it for using an arbitrary benchmark to determine the eco-efficiency of a firm and for being based on a simple average of added values. 


\section{Materials and Methods}

The initial modified SESG VA model [23] was based on the strengths of the SVA model [11] and was extended namely to include the weights of indicators, maximizing social and corporate governance indicators, and the ways of establishing targets (benchmarks) using the methods of Data Envelopment Analysis (DEA).

The methodology of research for determining SESG ${ }_{\mathrm{VA}}$ models is broken into four steps:

(1) Selection and reduction of ESG indicators through factor analysis.

(2) Assigning weights to a reduced set of ESG indicators.

(3) Setting a benchmark values.

(4) Evaluation of SESG $\mathrm{VA}_{\mathrm{A}}$ models quality on selected Czech manufacturing companies.

\subsection{Selection and Reduction of ESG Indicators}

Important components of the SVA model, as per Equation (1), are indicators that are in fact negative (unwanted) outputs of company production that are to be minimised. This can be considered as a weakness of the SVA model which does not contain indicators that positively define the sustainability of the company and, at the same time, it does not contain indicators in the field of corporate governance, i.e., it omits the fourth pillar of corporate sustainability [7]. For this reason, the maximisation of corporate governance and social indicators were included in the SESG $\mathrm{VA}_{\text {m }}$ model.

The details of the indicators selection methodology were presented in the work [7,23]. 25 absolute $I_{E S G i}$ performance indicators were identified which were subsequently reduced using one-dimensional and multi-dimensional statistical methods (exploratory factor analysis and confirmatory factor analysis) to $12 I_{E S G i}$ performance indicators. Table 1 shows a total of $11 I_{E S G i}$ performance indicators because the Number of terminated employees and Total number of employees indicators are merged into the $I S_{0} C_{2}$-Employee turnover indicator. Before EFA and PCA scales of $I_{E S G i}$ were modified so that higher values mean better results.

\subsection{Assigning Weights to ESG Indicators}

The reason for the modification of the SVA model [11] was one of its weaknesses that assumes that all of the indicators participate equally in the value added. It is the easiest way to deal with the allocation of weights and to assign the same weight to all indicators. Assigning equal weights assumes that each indicator contributes equally to creating value, but in the corporate reality, this is often not the case. A rather more exact approach is recommended to determine the exact weights, namely objective methods, expert approach or subjective methods. Since the model of sustainable value is significantly influenced by the choice of used environmental, social, and corporate governance performance indicators $\left(I_{E S G i}\right)$ and their assigned weights, this specific approach may lead to an attempt to influence purely statistical approaches. Some authors [24] recommended the expert approach since, in their view, weights that are assigned solely on the basis of exact approach do not necessarily reflect the actual relationships between indicators.

In order to determine the $w_{i}$ weights the authors initially applied the assignment of weights on the basis of the exact approach using factor scores from the Principal Component Analysis method [23].

In order to determine the weights in this article they applied the expert approach that appears to be more appropriate given the smaller number of indicators because it does not lower the resolution capacity of the respondent. This is why they used the views of experts in the manufacturing industry companies.

The weights of $I_{E S G i}$ indicators express in numeric values their importance for the sustainability of the company. The higher the importance of the indicator for sustainability, the higher is the value of its weight. Questionnaires were sent to a group of 40 experts in selected manufacturing companies and they were asked to assign weights to individual $I_{E S G i}$ indicators in the areas of environmental, social, and corporate governance. Experts expressed their opinions on the basis of 1-10 rating scale. 
The rating method was used to estimate the weights of indicators. The experts assigned the $b_{i}$ value to the $i$-th $I_{E S G i}$ indicator on the $<0 ; 10>$ scale. The higher the importance of the $I_{E S G i}$ for the decision-maker, the higher is the rating. The weight of the $i$-th indicator is calculated according to the formula Equation (2):

$$
w_{i}=\frac{b_{i}}{\sum_{i=1}^{k} b_{i}},
$$

The sum of $b_{i}$ numbers in the denominator is the sum of $k$ natural numbers.

The $w_{i}$ weights are standardised in Equation (3):

$$
\sum_{i=1}^{k} w_{N i}=1, \text { for } i=1,2, \ldots, k
$$

\subsection{Setting Benchmark Values}

Benchmarking is a fundamental element in the SESG ${ }_{\mathrm{VA}}$ model. In the SVA model, the authors Figge and Hahn [15], use the same general target values for all businesses that are derived from the results of the national economy.

In the article [23], the target values of the $\mathrm{SESG}_{\mathrm{VA}}$ model were determined using the Data Envelopment Analysis (DEA) through the Slack Based Measure additive model [25]. The main advantage of this model is that it prevents a situation where the unit reaches an effective score of 1 but is not efficient because one of its additive variables is not zero.

The advantage of using DEA for establishing the target values is the fact that the target values are set specifically for each company. The disadvantage of this approach is that the results are defined in relation to other companies included in the surveyed sample and as such the method is sensitive to the type of companies that are included in the sample. Another disadvantage limiting the practical application of this approach is that it is necessary to obtain data from a large number of companies which is difficult in a situation where companies do not publish data or publish it in various formats making an inter-company comparison difficult.

Given the limitations of the DEA method for determining benchmarks, other approaches will be applied. The $I_{E S G i}$ performance indicators are benchmarked against:

I. values of a so-called fictitious company;

II. industry average;

III. values of a company with the best economic results; and,

IV. values of a company with average economic results.

Assessing businesses in terms of their distance from the fictitious (ideal) company is an approach applied in the multi-criteria analysis of variants. The so-called fictitious company is mostly a hypothetical company that achieves the best possible values in all criteria. For the application of this approach in the context of sustainability, see for example [26].

When comparing the values with the industry average the target values are set at the level of average values of a group of companies, separately for each indicator. This creates an analogy to the fictitious company but with the average values of all $I_{E S G i}$. Another approach is to identify a particular company that achieves average values of the selected economic indicator and to compare the $I_{E S G i}$ performance indicators with values of the identified reference company.

The company that shows the best economic results should be set as a leader representing the best practice. In case of this benchmarking approach it is important to make sure that we do not identify a company that achieves high economic results at the expense of sustainability.

\subsection{Evaluating the Quality of the Sustainable Environmental, Social and Corporate Governance Value Added Model}

There are numerous methods for evaluating the quality of models with binary response variable, for example the Receiver Operating Characteristic curve, Gini index, the Kolmogorov-Smirnov statistic and others. 
Receiver Operating Characteristic curve (ROC) is used in psychology, sociology, economics, as well as in medicine [27] and the environmental area [28]. The ROC curve is a graphical representation of the specificity $S_{p}$ and sensitivity $S_{e}$. The ROC curve is formed by a set of all possible pairs $\left(S_{e}, 1-S_{p}\right)$ for various $s$ values $[29,30]$. When comparing several models we will choose the one for which the highest positioned ROC curve reaches 1 .

To compare ROC curves the area under the ROC curve known as AUC is successfully used. The higher the AUC, the better the SESG ${ }_{\mathrm{VA}}$ models differentiate between companies that create sustainable value and those that fail to do so. Since AUC is a part of a unit square its value will always be between 0 and 1 . We know from the result of a random predictor that AUC will never be less than 0.5 , and therefore AUC will achieve a value in the interval $(0.5 ; 1.0)$. The area under curve is determined by the relationship demonstrated in Equation (4):

$$
\mathrm{AUC}=\int_{0}^{1} \operatorname{ROC}(p) \mathrm{d} p,
$$

The accuracy of the test, i.e., the size of AUC, is determined by the following rating: 0.9-1.0 excellent; $0.8-0.9$ very good; $0.7-0.8$ good, $0.6-0.7$ sufficient; $0.5-0.6$ insufficient [30,31].

The Gini test (GI) is often preferred in the evaluation of model quality. The relationship between AUC and GI is described in the Equation (5) [30]:

$$
\mathrm{GI}=2 \mathrm{AUC}-1,
$$

GI assumes values in the interval $(0 ; 1)$. If it is zero, then it is a quite random ranking of cases, on the contrary, if it equals one, it is the ideal model which ranks good and bad cases perfectly. The closer the GI is to one, the better is the quality of the model.

Kolmogorov-Smirnov statistic (KS) is yet another tool for model quality evaluation. The KS test seeks the maximum vertical distance between two distribution functions. The KS test is defined in the relationship shown in the Equation (6):

$$
\mathrm{KS}=\max _{\mathrm{s}}(F(s \mid B)-F(s \mid G)),
$$

The KS statistic is the length of line that maximizes the distance between distribution functions $F(s \mid B)$ and $F(s \mid G)$. When displaying densities, this maximum separation would occur at the point where the densities cross because the extreme cases occur at the point where the derivative function is zero. Therefore $f(s * \mid B)-f(s * \mid G)=0$ on the maximizing score $s *$. Generally speaking, the distance between distribution functions will be shorter or equal to KS statistic and thus KS is the upper limit of the distance separating the conditional distributions [32]. In our case, in the SESG $\mathrm{VA}_{\mathrm{A}}$ models, the conditional distribution functions $F(s \mid G)$ will be used for companies that create sustainable value and $F(s \mid B)$ will be used for those that do not create sustainable value.

The disadvantage of GI, and also of AUC and KS statistic, is their abstractness. For example, the GI of a model has a value of 0.5 ; this information on its own does not have a great informative value. All that we can say based on this information is that this model has a higher quality than the model for which GI $=0.3$. Based on the GI we are not able (unlike in sensitivity and specificity) to quantify the added value of the model.

In order to verify the SESG $\mathrm{VA}$ model we obtained data on $219 \mathrm{EU}$ manufacturing companies for the year 2014 from their annual reports and voluntary reporting; see Appendix A.

Companies that reported remote values and companies that clearly could not create sustainable value, i.e., companies with negative economic value added, were removed from the sample for the sake of data quality. The number of companies in the sample was reduced to 66 and on these we evaluated the SESG $\mathrm{VA}$ model; see Appendix B. 


\section{Results and Discussion}

With respect to the benchmarking methods used in the modified SESG ${ }_{V A}$ model, it is appropriate to express the $I_{E S G i}$ indicators in relative terms. The $I_{E S G i}$ indicators are relative to the annual value added and the indicator $I_{S o c 2}-$ Employee turnover is designed on the basis of the Number of terminated employees and Total number of employees. $I_{E S G i}$ are listed in Table 1.

Table 1. $I_{E S G i}$ performance indicators used in the SESG $\mathrm{VA}_{\mathrm{A}}$ model.

\begin{tabular}{|c|c|c|}
\hline $\mathrm{I}_{\mathrm{ESGi}}$-Input Indicators & Unit & Expertly Defined Weights $w_{N i j}$ \\
\hline \multicolumn{3}{|c|}{$I_{\text {Eni }}$-Environmental indicators } \\
\hline $\begin{array}{l}I_{E n 1}-\text { Non-investment expenditures for the } \\
\text { protection of the environment }\end{array}$ & ['000 CZK] & 0.093 \\
\hline$I_{E n 2}-$ Total annual consumption of water & {$\left[\mathrm{m}^{3}\right]$} & 0.076 \\
\hline$I_{E n 3}-$ Total annual production of waste & {$[\mathrm{t}]$} & 0.099 \\
\hline$I_{E n 4}-$ Total annual production of hazardous waste & {$[\mathrm{t}]$} & 0.104 \\
\hline \multicolumn{3}{|c|}{$I_{\text {Soci }}$-Social indicators } \\
\hline $\begin{array}{l}I_{S o c 1}-\text { Total amount of money for charitable work } \\
\text { in support of local communities }\end{array}$ & {$\left[{ }^{\prime} 000 \mathrm{CZK}\right]$} & 0.067 \\
\hline$I_{S o c 2}$-Employee turnover & [number] & 0.089 \\
\hline$I_{S o c 3}-$ Education and training expenditures & {$\left[{ }^{\prime} 000 \mathrm{CZK}\right]$} & 0.084 \\
\hline \multicolumn{3}{|c|}{$I_{C g i}-C G$ indicators } \\
\hline$I_{C g 1}$-Information about financial results & [yes $=0.98 ;$ no $=0.02$ ] & 0.101 \\
\hline$I_{C g 2}$-Collective agreement & [yes $=0.53 ;$ no $=0.47]$ & 0.093 \\
\hline$I_{C g 3}-$ Reports from environmental and social areas & [yes $=0.60 ;$ no $=0.40]$ & 0.096 \\
\hline$I_{C g 4}-$ Code of ethics & [yes = 0.70; no = 0.30] & 0.098 \\
\hline
\end{tabular}

Earnings before Interest, Taxes, Depreciation and Amortization (EBITDA), or Value Added are used as economic (output) indicators in the SESG $\mathrm{VA}_{\mathrm{A}}$ model. EBITDA is the most robust indictor of profit and it is useful thanks to the possibility of comparing various companies in various sectors. The value added is in line with the EMAS recommendations concerning the design of key indicators. $I_{E c o i}$ are listed in Table 2.

Table 2. $I_{E c o i}$ economic output indicators in the SESGVA model.

\begin{tabular}{|c|c|}
\hline $\mathrm{I}_{\text {Ecoi }}$-Economic indicators & Unit \\
\hline $\mathrm{I}_{\mathrm{Eco1}}$-Earnings before Interest, Taxes, Depreciation and Amortization & [’000 CZK] \\
\hline $\mathrm{I}_{\mathrm{Eco} 2}-$ Value Added & [’000 CZK] \\
\hline
\end{tabular}

The modified $S E S G_{V A}$ model presented in this paper is based on the model that was published by Kocmanová et al. (2016). The SESG $\mathrm{VA}_{\mathrm{A}}$ calculation is as follows:

$$
\begin{gathered}
S E S G_{V A}=E n_{V A}+S o c_{V A}+C g_{V A}, \\
E n_{V A}=\sum_{r=1}^{R} w_{N i}\left(\frac{I_{E c o i}}{I_{E n i}}-\frac{I_{c c i}^{*}}{I_{E n i}^{*}}\right) I_{E n i}, \\
S o c_{V A}=\sum_{r=1}^{R} w_{N i}\left(\frac{I_{E c 0 i}}{I_{S o c i}}-\frac{I_{c c i}^{*}}{I_{S o c i}^{*}}\right) I_{S o c i}, \\
C g_{V A}=\sum_{r=1}^{R} w_{N i}\left(\frac{I_{E c o i}}{I_{C g i}}-\frac{I_{c c i i}^{*}}{I_{C g i}^{*}}\right) I_{C g i},
\end{gathered}
$$

on condition : $f(x)=\left\{\begin{array}{c}x, x \neq 0 \\ I_{E c o i}, x=0\end{array}\right.$, where $x=\left(\frac{I_{E c o i}}{I_{E S G i}}-\frac{I_{E c o i}^{*}}{I_{E S G i}^{*}}\right) I_{E S G i}$. 


$$
\text { Then } S E S G_{V A}=\sum_{r=1}^{R} w_{N i} x .
$$

where: $E n_{V A}$-Environmental Value of the company; $S o c_{V A}$-Social Value of the company; $C g_{V A}-$ Corporate Value of the company; $R$-Total amount of resources considered; $w_{N i}$-standardized weight of $i$-th indicator $I_{i j} ; I_{E c o i}$-Economic output of the company; $I_{E c o i}{ }^{*}-$ Economic output of benchmark; $I_{E n i}$ - Environmental resource of the company; $I_{E n i}{ }^{*}$-Benchmark value of environemntal resource; $I_{S o c i}$-Benchmark value of social resource; $I_{S o c i}{ }^{*}$-Social output of benchmark; $I_{C g i}$ - Corporate governance resource of company; $I_{C g i}{ }^{*}$ - Benchmark value of corporate governance indicator.

In total, ten $S E S G_{V A}$ models were created combining output economic indicators $I_{E c o i}$ with various methods of determining target values: five models of EBITDA SESG ${ }_{V A \_E B I T D A}$ and five models of Value Added SESG $G_{V A \_V a l u e A d d e d}$.

SESG $_{V A}$ models with EBITDA as an output economic indicator:

- $\quad$ model SESG VA_EBITDA_I $_{\text {I }}$ uses values of a fictitious (ideal) company as a benchmark;

- model SESGVA_EBITDA_II uses industry average as a benchmark;

- model SESGGA_EBITDA_III uses values of a company with the best economic results as a benchmark;

- model SESG_VA_EBITDA_IV uses values of a company with average economic results; and,

- model SESGVA_EBITDA_V uses values DEA target values as a benchmark.

SESG $_{V A}$ models with Value Added as an output economic indicator:

- model SESG VA_ValueAdded_I uses values of a fictitious (ideal) company as a benchmark;

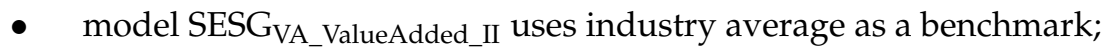

- model SESGVA_ValueAdded_III uses values of a company with the best economic results as a benchmark;

- model SESGVA_ValueAdded_IV uses values of a company with average economic results; and,

- model SESGVA_ValueAdded_V uses values DEA target values as a benchmark.

The summary of models and their designation are provided in Table 3.

Table 3. Modification of the SESGVA model.

\begin{tabular}{|c|c|c|}
\hline \multicolumn{3}{|c|}{ SESG $_{\text {VA }}$ Model } \\
\hline \multirow{2}{*}{ Benchmarking Method } & \multicolumn{2}{|c|}{$I_{E c o i}-$ Economic Indicators } \\
\hline & EBITDA & Value Added \\
\hline Fictitious (ideal) company & SESGVA_EBITDA_I & SESGVA_ValueAdded_I \\
\hline Industry average & SESG VA_EBITDA_II & SESG ${ }_{\text {VA_ValueAdded_II }}$ \\
\hline Best economic results & SESG VA_EBITDA_III & SESG VA_ValueAdded_III \\
\hline Average economic results & SESGVA_EBITDA_IV & SESG VA_ValueAdded_IV \\
\hline DEA target values & SESG VA_EBITDA_V & SESG VA_ValueAdded_V \\
\hline
\end{tabular}

It follows from the descriptive characteristics of individual models in Table 4 that the biggest difference in the values of sustainable value is achieved when using benchmarking values of the ideal

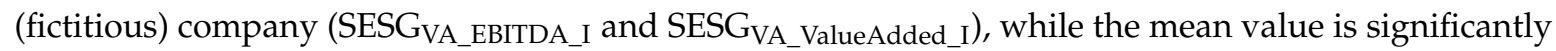
lower in these models when compared to other models. The results of the Bonferroni post hoc analysis showed that the differences in comparison with other SESG $_{\mathrm{VA}}$ models are statistically significant. The use of the ideal company for the sustainable value calculation is an extreme approach, since no company can achieve such target values and therefore the resulting sustainable value will always be negative. The variation margin is generally higher in the Value Added models than in EBITDA models, which is due to the nature of these economic indicators. 
Table 4. Descriptive characteristics of SESGVA models.

\begin{tabular}{cccccc}
\hline \multirow{2}{*}{ SESG } & \multicolumn{4}{c}{ Descriptive Statistics [CZK] } \\
\cline { 2 - 6 } & $\mathbf{N}$ & Mean & Std. Deviation & Minimum & Maximum \\
\hline SESGVA_EBITDA_I & 66 & $-239,474,453,000$ & $408,826,335,300$ & $-1,813,765,457,000$ & $-290,323,541$ \\
SESG & 66 & $-37,774$ & 516,338 & $-1,857,855$ & $1,297,521$ \\
SESG_EBITDA_II & 66 & $-52,486,346$ & $112,186,950$ & $-714,867,082$ & $1,411,015$ \\
SESG_EBITDA_III & 66 & $-308,220$ & 805,946 & $-2,399,334$ & $1,325,365$ \\
SESG_EBITDA_IV & 66 & $-5048,824$ & $16,858,742$ & $-99,445,057$ & $1,411,015$ \\
SESG_EBITDA_V & 66 & $-521,809,651,500$ & $890,823,681,800$ & $-3,952,155,479,000$ & $-632,234,851$ \\
SESG_ValueAdded_I & 66 & $-79,821$ & $1,126,239$ & $-3,918,260$ & $2,742,060$ \\
SESG_ValueAdded_II & 66 & $-24,908,504$ & $35,823,466$ & $-158,605,092$ & $2,325,851$ \\
SESG_ValueAdded_III & 66 & $-500,906$ & $1,612,190$ & $-4,492,450$ & $2,721,710$ \\
SESG_ValueAdded_IV & 66 & $-6,091,975$ & $30,983,209$ & $-249,152,178$ & $2,582,878$ \\
\hline
\end{tabular}

The generally most lenient approach to determining the target value is the definition of benchmarks on the level of industry average for each indicator separately (SESGVA_EBITDA_II and SESG_VA_ValueAdded_II).

The Spearman method is used for the calculation of the SESG VA $_{\text {A }}$ models correlation; see Table 5. In fact, this method is more robust and more appropriate for application on real data.

Table 5. Correlation matrix for SESG ${ }_{V A}$ models.

\begin{tabular}{|c|c|c|c|c|c|c|c|c|c|}
\hline SESG $_{\mathrm{VA}}$ Models & (1) & (2) & (3) & (4) & (5) & (6) & (7) & (8) & (9) \\
\hline (1) SESGVA_EBITDA_I & & & & & & & & & \\
\hline (2) SESG VA_EBITDA_II & 0.929 & & & & & & & & \\
\hline (3) SESGVA_EBITDA_III & 0.739 & 0.728 & & & & & & & \\
\hline (4) SESG VA_EBITDA_IV & 0.847 & 0.890 & 0.858 & & & & & & \\
\hline (5) SESG VA_EBITDA_V & -0.014 & 0.022 & 0.253 & 0.197 & & & & & \\
\hline (6) SESG VA_ValueAdded_I & 1.000 & 0.929 & 0.739 & 0.847 & -0.014 & & & & \\
\hline (7) SESG_VA_ValueAdded_II & 0.929 & 0.932 & 0.826 & 0.961 & 0.087 & 0.929 & & & \\
\hline (8) SESGVA_ValueAdded_III & 0.883 & 0.859 & 0.932 & 0.946 & 0.201 & 0.883 & 0.942 & & \\
\hline (9) SESG VA_ValueAdded_IV & 0.856 & 0.869 & 0.874 & 0.986 & 0.165 & 0.856 & 0.969 & 0.959 & \\
\hline (10) SESG_VA_ValueAdded_V & -0.014 & 0.006 & 0.279 & 0.212 & 0.831 & -0.014 & 0.093 & 0.203 & 0.187 \\
\hline
\end{tabular}

The resulting values of individual SESG ${ }_{\mathrm{VA}}$ models are highly correlated with each other, with the exception of models that use the target values defined by the DEA method (SESGVA_EBITDA_V

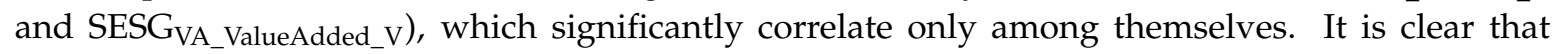
the DEA targets provide different results in comparison with other models. Repeated measures ANOVA was performed with a Greenhouse-Geisser correction testing the null hypothesis H0: SESG models have no significant effect on the sustainable value results. The results show there is a statistically significant difference between SESG $\mathrm{VA}$ models $(F(1,65)=22.645, p=0.000)$. Almost $26 \%$ of variability in values is explained by the applied model $\left(\eta^{2}=0.258\right)$. Results of Bonferroni post hoc test showed that benchmarking models with ideal values (fictitious companies) (SESGEA_EBITDA_I and SESG VA_ValueAdded_I $_{\text {) yield statistically significantly lower values compared to other SESG }}$ VA models. For $\mathrm{SESG}_{\mathrm{VA}}$ models using other benchmarking methods (e.g., industry average, values of a company with the best economic results, values of a company with average economic results, and DEA target values) the result is not significantly influenced by the choice of economic indicator, in comparison, there are no significant differences between these methods.

\section{Evaluation of SESG ${ }_{V A}$ Models Quality}

A sample containing SESG $_{\mathrm{VA}}$ models calculation data was subjected to statistical evaluation. The sample included 66 companies in the manufacturing industry. In this sample, 36 companies were identified as companies that are geared towards sustainability and 30 companies that are not. 
Companies were selected based on the calculation of the composite "corporate sustainability index" $\left(I_{C S}\right)$ indicator for the measurement and evaluation of sustainability of the manufacturing industry [33].

Results of the calculation of SESG $\mathrm{VA}$ models sustainable value were used for the evaluation of the model quality. The ROC curves are the graphic representation of SESG VA_EBITDA_I

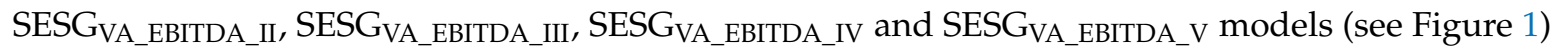
and SESG VA_ValueAdded_I SESG VA_ValueAdded_II, SESG VA_ValueAdded_III, SESGVA_ValueAdded_IV and

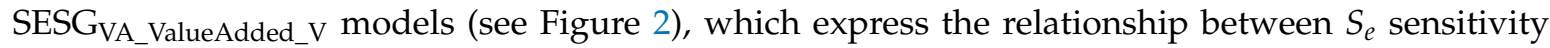
and 1-specificity $S_{p}$. Thus the point of reference is a unit square whose vertical axis represents the $S_{e}$ sensitivity and the horizontal axis represents the value of 1-specificity $S_{p}$. The ROC curve represents the combination of sensitivity and specificity values.

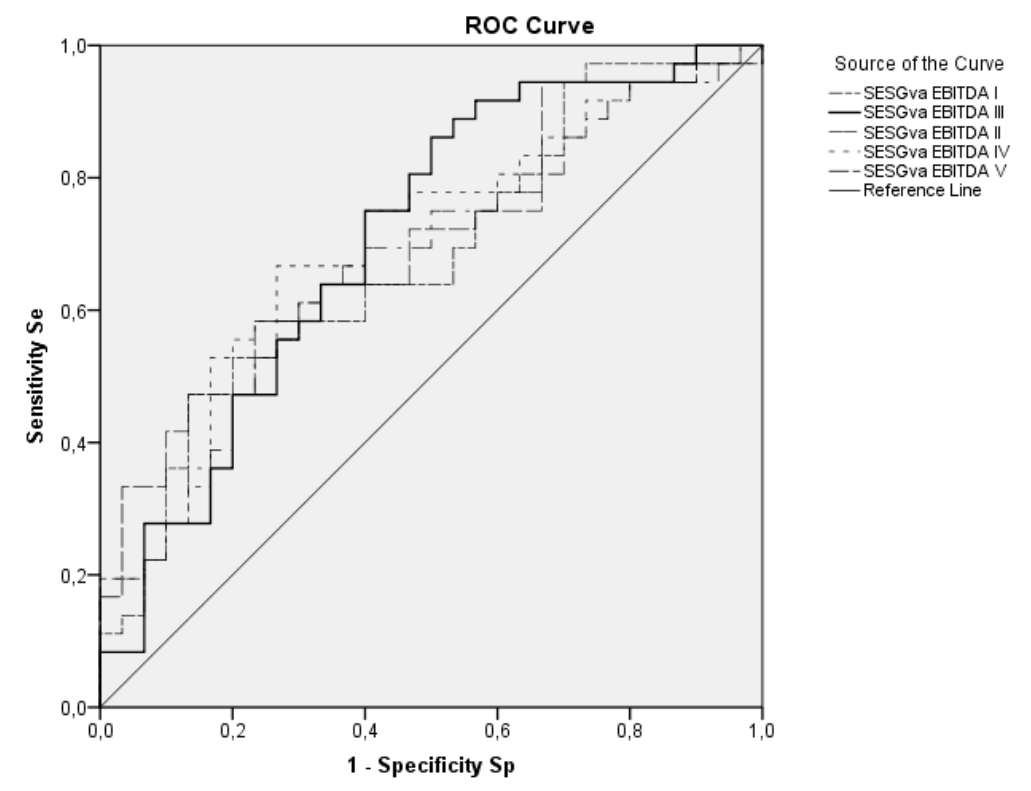

Figure 1. ROC curves of SESGVA_EBITDA models.

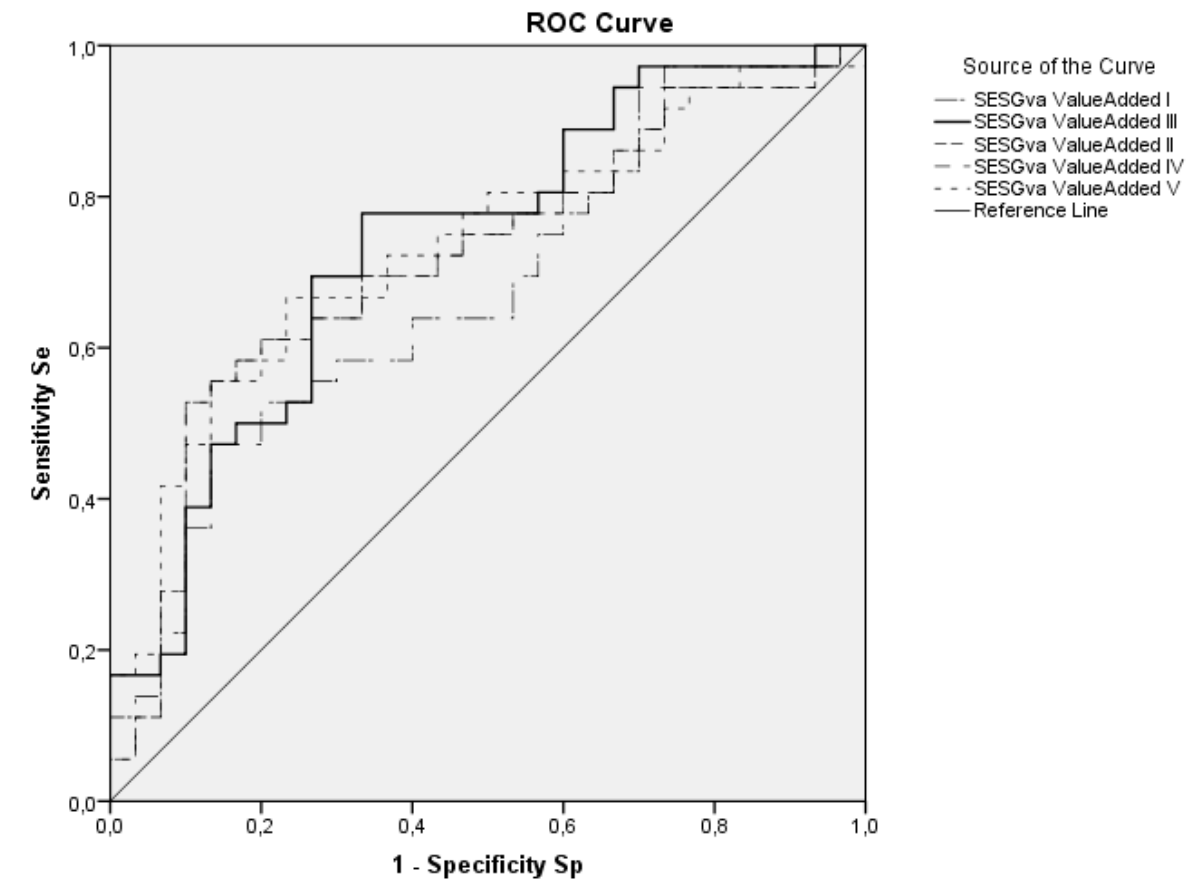

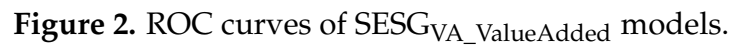


SESG $_{V A \_E B I T D A}$ ROC curves models in Figure 1 show the sufficient quality of models. SESG VA_ValueAdded in Figure 2 show a very good quality of models. The values of AUC, Gini index and Kolmogorov-Smirnov statistic of individual $\mathrm{SESG}_{\mathrm{VA}}$ models indicate the accuracy of the models; see Table 6 .

Table 6. Comparison of SESG $\mathrm{VA}$ models.

\begin{tabular}{cccc}
\hline Test Result Variable(s) & Area under the Curve (AUC) & Gini Index (GI) & $\begin{array}{c}\text { Kolmogorov-Smirnov } \\
\text { Statistic (KS) }\end{array}$ \\
\hline SESGVA_EBITDA_I & 0.677 & 0.354 & 0.339 \\
SESG_VA_EBITDA_II & 0.675 & 0.350 & 0.316 \\
SESGVA_EBITDA_III & 0.706 & 0.412 & 0.361 \\
SESGVA_EBITDA_IV & 0.704 & 0.408 & 0.400 \\
SESGVA_EBITDA_V & 0.698 & 0.396 & 0.350 \\
SESGVA_ValueAdded_I & 0.677 & 0.354 & 0.334 \\
SESGVA_ValueAdded_II & 0.716 & 0.432 & 0.428 \\
SESGVA_ValueAdded_III & 0.736 & 0.472 & 0.445 \\
SESG & 0.710 & 0.420 & 0.414 \\
SESG_ValueAdded_IV & 0.734 & 0.468 & 0.434 \\
\hline
\end{tabular}

It is SESG VA_ValueAdded_III $_{\text {that }}$ appears to be the most suitable model. Other methods indicate that

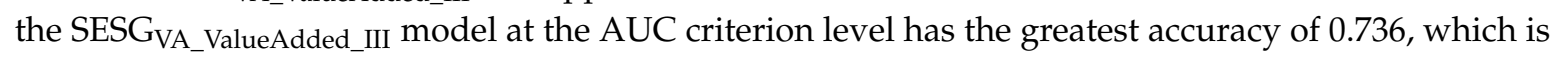
close to the ideal value. Based on the AUC $=0.736$, the Gini index was calculated with the resulting value of 0.472 . The result of Kolmogorov-Smirnov statistic equals 0.445 . Other conclusions from the

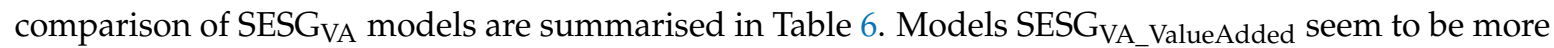
reliable models for the evaluation of sustainable value added in the manufacturing industry than alternative models SESG VA_EBITDA.

\section{Conclusions}

Value-oriented strategic management that is aimed at owners with the objective to maximize equity value is becoming obsolete. In value-based strategic management, value-creation effects of ESG factors are being more and more appreciated as a result of pressure from stakeholders. New models taking into account non-financial strategic factors of success that significantly influence the economic success of the company are being developed [15].

The paper presents a new approach to measure sustainable value based on the Sustainable Value Added concept [11,15-17]. The Sustainable Environmental, Social and Corporate Governance Value Added model makes it possible to measure the value of ESG indicators in monetary terms, relative to an established benchmark.

The advantage of the SESG ${ }_{\mathrm{VA}}$ model is that it gathers individual ESG indicators into single quantified information. The model is designed primarily for investors, owners, and all stakeholders who need relevant information about the corporate sustainability in their decision-making.

A possible disadvantage of the model lies in the choice of ESG indicators. The presented model was specifically designed for the manufacturing industry. Application of the model to other sectors of economic activities is possible after its revision, verification of the revised model's relevance, and possibly the modification of the indicators. Indicator weighs can be assigned using either an expert judgement or a statistical approach. Results of SESG ${ }_{\mathrm{VA}}$ model testing show that there are differences in weight values, but they are not statistically significant.

A key element of the SESG $\mathrm{VA}$ model is benchmarking. In the previous model [23], DEA was used to calculate target values for each company separately. The advantage of the specific nature of target values was counterbalanced by excessive requirements for data, which limits the practical applicability of the model. This article presented four other alternative approaches to setting benchmarks that partially overcome the problem associated with DEA. A positive finding is that the accuracy of the 
model is not significantly affected by the choice of the benchmarking method and, according to the statistics that were used, all of the models show sufficient quality.

Acknowledgments: This paper is supported by grant No. 17-23448S Modelling and Simulation of Sustainable Investment Decision-making of The Czech Science Foundation.

Author Contributions: Both authors contributed to research design. Alena Kocmanová contributed to the methodology section.

Conflicts of Interest: The authors declare no conflict of interest.

\section{Appendix A}

\begin{tabular}{lcc}
\hline Criteria & $N$ & $\%$ \\
\hline NACE & & \\
C10-Manufacture of food products & 7 & 3.2 \\
C11-Manufacture of beverages & 11 & 5.0 \\
C13-Manufacture of textiles & 6 & 2.7 \\
C20-Manufacture of chemicals and chemical products & 16 & 7.3 \\
C22-Manufacture of rubber and plastic products & 5 & 2.3 \\
C23-Manufacture of other non-metallic mineral products & 8 & 3.7 \\
C24-Manufacture of basic metals & 19 & 8.7 \\
C25-Manufacture of fabricated metal products & 55 & 25.1 \\
C26-Manufacture of computer, electronic and optical products & 22 & 10.0 \\
C27-Manufacture of electrical equipment & 26 & 11.9 \\
C28-Manufacture of machinery and equipment n.e.c. & 44 & 20.1 \\
\hline Number of Employees in 2014 & & \\
1-250 & 59 & 26.9 \\
251-1000 & 124 & 56.6 \\
1001-1750 & 21 & 9.6 \\
1751-2500 & 5 & 2.3 \\
More than 2501 & 7 & 3.2 \\
\hline
\end{tabular}

\section{Appendix B}

\begin{tabular}{lcc}
\hline Criteria & $N$ & $\%$ \\
\hline NACE & & \\
C10-Manufacture of food products & 1 & 1.52 \\
C11-Manufacture of beverages & 5 & 7.58 \\
C13-Manufacture of textiles & 1 & 1.52 \\
C20-Manufacture of chemicals and chemical products & 8 & 12.12 \\
C22-Manufacture of rubber and plastic products & 1 & 1.52 \\
C23-Manufacture of other non-metallic mineral products & 4 & 6.06 \\
C24-Manufacture of basic metals & 6 & 9.09 \\
C25-Manufacture of fabricated metal products & 9 & 13.64 \\
C26-Manufacture of computer, electronic and optical products & 2 & 3.03 \\
C27-Manufacture of electrical equipment & 14 & 21.21 \\
C28-Manufacture of machinery and equipment n.e.c. & 15 & 22.73 \\
Number of Employees in 2014 & & \\
1-250 & 21 & 31.82 \\
251-1000 & 34 & 51.52 \\
1001-1750 & 2 & 3.03 \\
1751-2500 & 2 & 3.03 \\
More than 2501 & 7 & 10.61 \\
\hline
\end{tabular}




\section{References}

1. Perrini, F.; Tencati, A. Sustainability and stakeholder management: The need for new corporate performance evaluation and reporting systems. Bus. Strategy Environ. 2006, 15, 296-308. [CrossRef]

2. Sharma, S.; Henriques, I. Stakeholder influences on sustainability practices in the Canadian forest products industry. Strateg. Manag. J. 2005, 26, 159-180. [CrossRef]

3. Elkington, J. Cannibals with Forks: The Triple Bottom Line of the 21st Century; New Society Publishers: Stoney Creek, CT, USA, 2008.

4. Aurer, T. Sustainability in Context of Knowledge Society and Demography; Schweizer Arbeitgeber Employeur Suisse Imprenditore Svizzero; Zentralverband Schweizerischer Arbeitsgeber-Organisationen: Zurich, Switzerland, 2003.

5. Schaltegger, S.; Wagner, M. Managing sustainability performance measurement and reporting in an integrated manner. In Sustainability Accounting and Reporting; Springer: Dordrecht, The Netherlands, 2006.

6. Buys, L.; Mengersen, K.; Johnson, S.; van Buuren, N.; Chauvin, A. Creating a Sustainability Scorecard as a predictive tool for measuring the complex social, economic and environmental impacts of industries, a case study: Assessing the viability and sustainability of the dairy industry. J. Environ. Manag. 2014, 133, 184-192. [CrossRef] [PubMed]

7. Pavláková Dočekalová, M.; Kocmanová, A. Composite indicator for measuring corporate sustainability. Ecol. Indic. 2016, 61, 612-623. [CrossRef]

8. Zhou, L.; Tokos, H.; Krajnc, D.; Yang, Y. Sustainability performance evaluation in industry by composite sustainability index. Clean Technol. Environ. Policy 2012, 14, 789-803. [CrossRef]

9. Singh, R.K.; Murty, H.R.; Gupta, S.K.; Dikshit, A.K. Development of composite sustainability performance index for steel industry. Ecol. Indic. 2007, 7, 565-588. [CrossRef]

10. Krajnc, D.; Glavič, P. How to compare companies on relevant dimensions of sustainability. Ecol. Econ. 2005, 55, 551-563. [CrossRef]

11. Figge, F.; Hahn, T. The Cost of Sustainability Capital and the Creation of Sustainable Value by Companies. J. Ind. Ecol. 2005, 9, 47-58. [CrossRef]

12. Meluzín, T.; Zinecker, M. Research into Determinants Influencing IPO Decisions on the Polish Capital Market. Betriebswirtschaftliche Forsch. Prax. 2014, 66, 652-671.

13. Meluzín, T.; Zinecker, M.; Lace, N. Going Public: Key Factors to Consider by IPO Candidates on Emerging Markets of Poland and the Czech Republic. Eng. Econ. 2016, 27, 392-404. [CrossRef]

14. Porter, M.E.; Kramer, M.R. Creating Shared Value. Harv. Bus. Rev. 2011, 89, 62-77.

15. Figge, F.; Hahn, T.; Schaltegger, S.; Wagner, M. The sustainability balanced scorecard-linking sustainability management to business strategy. Bus. Strat. Environ. 2002, 11, 269-284. [CrossRef]

16. Figge, F.; Hahn, T. Sustainable Value Added-Ein neues Maß des Nachhaltigkeitsbeitrags von Unternehmen am Beispiel der Henkel KGaA. Vierteljahrsh. Wirtsch. 2004, 73, 126-141. (In German) [CrossRef]

17. Hahn, T.; Figge, F.; Barkemeyer, R. Sustainable Value creation among companies in the manufacturing sector. Int. J. Environ. Technol. Manag. 2007, 7, 496-512. [CrossRef]

18. Rhouma, A.B. Sustainable Value in Europe: Sustainability Performance of the Czech Republic versus the Europe of Fifteen. E + M Ekon. Manag. 2010, 4, 16-29.

19. Van Passel, S.; Van Huylenbroeck, G.; Lauwers, L.; Mathijs, E. Sustainable value assessment of farms using frontier efficiency benchmarks. J. Environ. Manag. 2009, 90, 3057-3069. [CrossRef] [PubMed]

20. Kuosmanen, T.; Kuosmanen, N. How not to measure sustainable value (and how one might). Ecol. Econ. 2009, 69, 235-243. [CrossRef]

21. Ang, F.; Van Passel, S. The Sustainable Value approach: A clarifying and constructive comment. Ecol. Econ. 2010, 69, 2303-2306. [CrossRef]

22. Laszlo, C. Sustainable Value. Probl. Sustain. Dev. 2008, 3, $25-29$.

23. Kocmanová, A.; Pavláková Dočekalová, M.; Škapa, S.; Smolíková, L. Measuring Corporate Sustainability and Environmental, Social, and Corporate Governance Value Added. Sustainability 2016, 8, 945. [CrossRef]

24. Saisana, M.; Tarantola, S. State-of-the-Art Report on Current Methodologies and Practices for Composite Indicator Development; European Commission, Joint Research Centre: Ispra, Italy, 2006.

25. Cooper, W.W.; Seiford, L.M.; Tone, K. Introduction to Data Envelopment Analysis and Its Uses: With DEA-Solver Software and References; Springer: New York, NY, USA, 2006. 
26. Afful-Dadzie, A.; Afful-Dadzie, E.; Turkson, C. A TOPSIS extension framework for re-conceptualizing sustainability measurement. Kybernetes 2016, 45, 70-86. [CrossRef]

27. Zweig, M.H.; Campbell, G. Receiver-operating characteristic (ROC) plots: A fundamental evaluation tool in clinical medicine. Clin. Chem. 1993, 39, 561-577. [PubMed]

28. Peterson, A.T.; Papeş, M.; Soberón, J. Rethinking receiver operating characteristic analysis applications in ecological niche modelling. Ecol. Model. 2008, 213, 63-72. [CrossRef]

29. Hebák, P. Vícerozměrné Statistické Metody, 2rd ed.; Informatorium: Praha, Czech Republic, 2007; p. 253.

30. Fawcett, T. An introduction to ROC analysis. Pattern Recogn. Lett. 2006, 27, 861-874. [CrossRef]

31. Meloun, M.; Militký, J. Kompendium Statistického Zpracování dat: Metody a Řešené Úlohy; Academia: Praha, Czech Republic, 2006; p. 982.

32. Berry, M.J.; Linoff, G. Data Mining Techniques; Wiley: New York, NY, USA, 1997; p. 434.

33. Kocmanová, A.; Pavláková Dočekalová, M.; Simanavičiené, Ž. Corporate Sustainability Measurement and Assessment of Czech Manufacturing Companies using a Composite Indicator. Eng. Econ. 2017, 28, 88-100. [CrossRef]

(C) 2018 by the authors. Licensee MDPI, Basel, Switzerland. This article is an open access article distributed under the terms and conditions of the Creative Commons Attribution (CC BY) license (http:/ / creativecommons.org/licenses/by/4.0/). 